\title{
FUNCIONALISMO TRADUTÓRIO: IMPLICAÇÕES TEÓRICAS E PRÁTICAS
}

\section{TRANSLATION FUNCTIONALISM: THEORETICAL AND PRACTICAL SIGNIFICANCE}

\author{
Rafael Ferreira da Silva \\ Universidade Federal do Ceará \\ Fortaleza, Ceará, Brasil \\ Bill Bob Arinos Lima e Sousa \\ Instituto Federal de Educação, Ciência e Tecnologia do Ceará \\ Fortaleza, Ceará, Brasil
}

\begin{abstract}
RESUMO: Este artigo discute a perspectiva de tradução funcionalista com bases alemãs. Para isso, abordamos o seu surgimento (REISS, 2004; VERMEER, 2004), bem como o seu desenvolvimento (NORD, 2001; 2005; 2006a; 2006b; 2009; 2010; 2012; 2016). Analisamos as implicações teóricas do funcionalismo tradutório para o campo dos Estudos da Tradução e mostramos algumas aplicações práticas desse quadro teórico. Observou-se que essa abordagem tradutória pode ser bastante útil ao ensino de língua estrangeira (LE) e à tradução literária.
\end{abstract}

PALAVRAS-CHAVE: Tradução; Funcionalismo; Ensino; Literatura

\begin{abstract}
This paper discusses the perspective of functionalist translation (with German foundations). In order to do that, we approach its emergence (REISS, 2004; VERMEER, 2004), as well as its development (NORD 2001; 2006; 2006a; 2006b; 2009; 2010; 2012; 2016). We analyze the theoretical significance of translation functionalism for Translation Studies field and we present some practical applications of this theoretical framework. It was observed that this translation approach may be very useful for foreign language teaching and for literary translation.
\end{abstract}

KEYWORDS: Translation; Functionalism; Teaching; Literature

\footnotetext{
Este trabalho contou com o apoio do CNPq, através do Edital Universal - Chamada $\mathrm{MCTI} / \mathrm{CNPq} \mathrm{N}^{\mathrm{o}} 14 / 2014$.
} 


\section{INTRODUÇÃO}

O conceito de tradução, há muito discutido em cartas, prefácios, e outros textos que datam de séculos, vem sendo a cada dia revisto e rediscutido. Ao examinarmos a literatura que trata do assunto (FAVERI; TORRES, 2004; GUERINI; ARRIGONI, 2005; FURLAN, 2006; HEIDERMANN, 2010), verificamos que essa discussão permaneceu escassa e fragmentada por muitos séculos. Percebemos, também, que nas últimas décadas esse debate ampliou-se através da emersão dos Estudos da Tradução como novo campo de conhecimento acadêmico (VENUTI, 2004). As variáveis envolvidas na atividade de tradução fazem com que sua definição seja complexa e múltipla. Não é proposta de este trabalho forjar mais um conceito dessa atividade, antes, pretende-se, aqui, discutir a perspectiva funcional de tradução e seus pressupostos aplicados ao ensino de língua estrangeira (LE) e à tradução literária.

Para isso, traçamos um breve histórico do desenvolvimento do funcionalismo tradutório com bases alemãs. Em seguida, discutimos essa teoria a partir da perspectiva de Christiane Nord (2001; 2005; 2006a; 2006b; 2009; 2010; 2012; 2016), a qual se autointitula representante da segunda geração funcionalista (NORD, 2012, p. 26). Por fim, tocamos a aplicabilidade desse quadro teórico ao ensino de LE e à tradução literária.

\section{SURGIMENTO DA TEORIA FUNCIONALISTA DA TRADUÇÃO}

Abordagens funcionalistas em tradução, de acordo com Nord (2001, p. 4), não são, inteiramente, um produto do século XX. A história mostra que, em diferentes épocas, desde Cícero, São Jerônimo e Lutero, principalmente com traduções literárias e bíblicas, já havia a noção de que situações diversas requerem decisões diferentes no trabalho tradutório, abordagens com traços de orientação prospectiva.

O funcionalismo tradutório, com bases alemãs, tem como forte referência os pressupostos do funcionalismo linguístico - "Caracteriza-se pela crença de que a estrutura fonológica, gramatical e semântica das línguas é determinada pelas funções que têm que exercer nas sociedades em que operam" (LYONS, 1987, p. 207). Essa perspectiva prospectiva da Tradução ${ }^{1}$ põe em relevo os elementos pragmáticos das situações comunicativas, desconstruindo a relação histórica de servilismo entre texto-fonte (TF) e texto-alvo (TA).

A abordagem funcionalista de tradução foi sugerida inicialmente por Reiss (1971) quando a autora incluiu em seu modelo de crítica tradutória a função especial de uma tradução, “[...] como uma exceção ao conceito geral de

\footnotetext{
${ }^{1}$ A Tradução enquanto disciplina surge, apenas, por volta dos anos de 1970; antes disso, fora tratada como um subgrupo da Literatura Comparada e da Linguística (SNELLHORNBY 2010).
} 
equivalência, o qual ela jamais havia contestado"² (NORD, 2012, p. 27, tradução nossa ${ }^{3}$ ). Dentre as possibilidades de retextualização, Reiss (2004) argumenta que para produzirmos um texto de tradução (TT) funcionalmente equivalente, faz-se necessária a manutenção da função do $\mathrm{TF}$, seja ela referencial, expressiva ou conativa. Porém, quando para atender o objetivo tradutório precisa-se produzir um TT com função diferente da do TF, a autora orienta que uma tipologia de tradução substituiria a tipologia textual e o objetivo tradutório, escopo, não seria obter um TA funcionalmente equivalente, mas com a forma adequada à "função estrangeira". A autora, dessa forma, desafia o conceito de "equivalência" nos Estudos da Tradução.

No final dos anos de 1970, alinhado a esses princípios, Hans Vermeer (2004) leciona que a tradução é uma ação e como toda ação tem um objetivo, um escopo. A partir dessa premissa, o autor desenvolve a Teoria do Escopo. O termo skopos "é o termo técnico para o objetivo ou propósito de uma tradução." 4 (VERMEER, 2004, p. 221). Essa teoria prevê que, na ação tradutória, um cliente, chamado de iniciador, procura um tradutor porque o primeiro precisa que o último produza um TT para atender a um determinado objetivo. Esse cliente informa ao tradutor acerca do objetivo do TT. O tradutor, por sua vez, no papel de especialista, informa ao cliente sobre as peculiaridades do serviço. Nessa negociação, as partes geram o encargo de tradução, que deve conter todas as informações necessárias à produção do TT. O encargo de tradução está em grande medida subordinado ao objetivo da tradução, ao seu escopo (VERMEER, 2004).

Discípula dos autores supracitados, Christiane Nord, mais recentemente, condensou e expandiu os pressupostos funcionalistas da tradução. A teoria nordiana, partindo da teoria do escopo, explora a investigação dos elementos intratextuais e extratextuais do TF e trabalha com conceitos como "oferta de informação" e "lealdade", seguindo uma linha de pensamento que entende o TT de uma perspectiva prospectiva ${ }^{5}$ (NORD 2001; 2005; 2006a; 2006b; 2009; 2010; 2012; 2016). A autora é responsável pela formulação de uma teoria forte que prevê diversas situações em que o tradutor pode se encontrar e que apresenta soluções tradutórias plausíveis.

\footnotetext{
${ }^{2}$ Nord (2012) leciona, entretanto, que as bases teóricas para o que se tornaria o Funcionalismo nos Estudos da Tradução foram construídas por Vermeer, com a teoria do escopo, Holz-Mänttäri, com a teoria da ação tradutória e por Göhring, a partir dos estudos sobre comunicação intercultural, aplicados à tradução e à interpretação.

${ }^{3}$ As traduções contidas neste trabalho são de nossa autoria e servem para fins meramente didáticos.

${ }_{5}^{4}[\ldots]$ is a technical term for the aim or purpose of a translation.

${ }^{5}$ No fim dos anos de 1970, com a "virada cultural", duas linhas acadêmicas desenvolveram uma visão "prospectiva", que não se concentrava no TF, mas no status e função da tradução na cultura alvo. Uma linha estava centrada nos Países Baixos com Toury e os Estudos Descritivos da Tradução e a outra na Alemanha com Vermeer e a Abordagem Funcionalista em Tradução. Apesar de desenvolverem pesquisas independentes, em meados dos anos 80 , as duas linhas apresentaram várias percepções em comum, incluindo a ênfase no contexto cultural de tradução sobrepondo o material linguístico do TF (SNELL-HORNBY, 2010).
} 


\section{TEORIA NORDIANA DE TRADUÇÃO}

Nord (2005) entende a tradução como um processo de comunicação intercultural ${ }^{6}$. Esse processo, segundo a autora, inicia-se a partir da produção do $\mathrm{TF}$. Assim, quando traduzimos é fundamental que tenhamos acesso às informações de produção do TF bem como às informações de produção do TA (encargo de tradução). Nesse sentido, Nord (2005) assevera que o tradutor, além de ser bilíngue, deve ser também bicultural, um profissional capaz de preencher o que a autora chama de vala cultural (Figura 1).

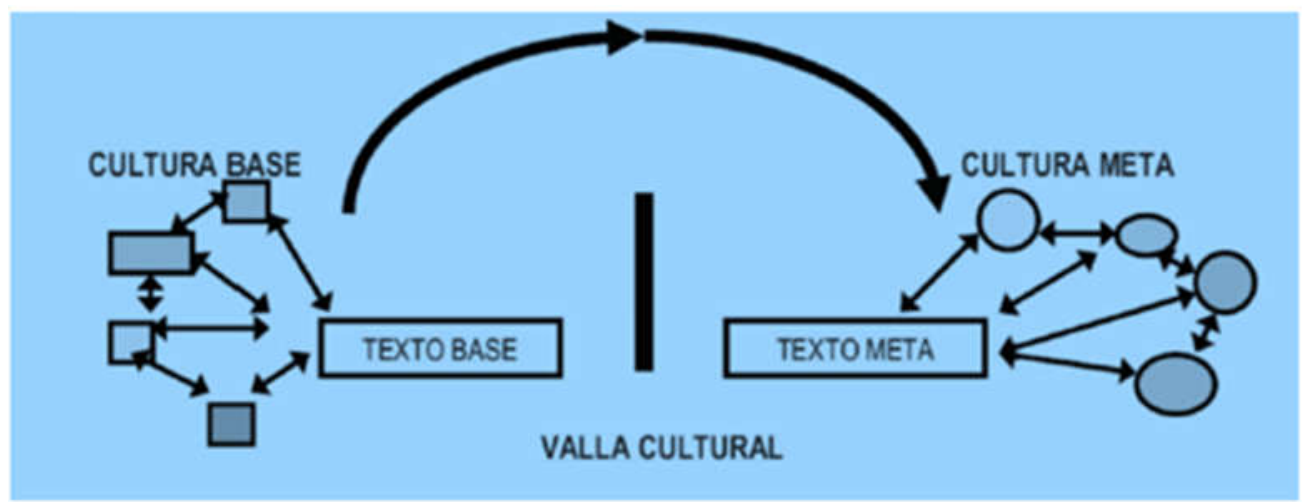

Figura 1: Polissistemas Textuais. Fonte: Nord (2010, p. 11)

Para termos acesso às informações de produção do $\mathrm{TF}^{7}$, Nord (2005) orienta que façamos uma série de questionamentos. A fim de descobrir informações de ordem extratextual perguntamos sobre o autor e o emissor do TF, "quem?"; sobre as intenções do autor/emissor do TF, "para que?"; sobre o público/receptor ao qual o TF é direcionado, "para quem"?; sobre a mídia ou o suporte pelo qual o TF é comunicado, "por que meio?"; sobre o lugar e o tempo de produção do TF, “onde?" e "quando?"; e sobre o motivo de comunicação do TF, "por quê?". A conjunção das informações obtidas através desses questionamentos nos direciona a uma resposta para a pergunta que toca a função do TF: "com que função?" (NORD, 2005, p. 42).

Ao fazermos uma análise dos elementos extratextuais de um dado TF, construímos uma base sólida da qual pode resultar uma interpretação consistente, que dialogue com os fatores que estão em torno do texto a ser traduzido. Essa análise permite ao tradutor perceber intenções contidas em determinadas palavras

\footnotetext{
${ }^{6}$ Partindo do fato de que os conceitos de cultura são múltiplos e contraditórios (SILVA; SILVA; 2009), procuramos evitar uma discussão extensa sobre o assunto optando, neste trabalho, pela adoção da definição que se segue, por entendermos que a partir dela podemos discutir os temas deste estudo. Segundo Alfredo Bosi, [...] "cultura é o conjunto de práticas, de técnicas, de símbolos e de valores que devem ser transmitidos às novas gerações para garantir a convivência social" (SILVA; SILVA; 2009, p. 86). Esse conceito é entendido, aqui, como algo localizado em um tempo e em um espaço.

${ }^{7} \mathrm{Na}$ figura 1, usa-se a terminologia "texto base" e "texto meta" porque trata-se de uma publicação em espanhol.
} 
ou expressões, as remissões feitas no TF; como este é influenciado por valores, costumes e pela história do contexto de partida.

Já a análise dos fatores intratextuais do TF é feita indagando-se sobre o tema do texto, "qual é o assunto?"; sobre o conteúdo do texto, "o que o texto traz?"; sobre as pressuposições de conhecimento feitas pelo autor em relação ao seu público, "que conhecimento o leitor tem/não tem?"; sobre a composição ou construção do texto, "qual é a ordem?"; sobre o elementos não-linguísticos ou paralinguísticos que acompanham o texto, "que elementos não-verbais são usados?"; sobre as características lexicais e sintáticas encontradas no texto, "que palavras são usadas?" e "que tipo de frases são usadas?"; e sobre as características suprassegmentais de entonação e prosódia, "qual é o tom?" (NORD, 2005, p. 42).

Ao fazermos uma análise dos elementos extratextuais de um dado TF, construímos uma base sólida da qual pode resultar uma interpretação consistente, que dialogue com os fatores que estão em torno do texto a ser traduzido. Essa análise permite ao tradutor perceber intenções contidas em determinadas palavras ou expressões, as remissões feitas no TF; como este é influenciado por valores, costumes e pela história do contexto de partida.

No que se refere às informações de produção do TA, estas devem ser negociadas entre o iniciador (cliente) e o tradutor $^{8}$ - configurando o chamado "encargo de tradução". Nord $(2005 ; 2009)$ explica que muitas das vezes o escopo de tradução não é atingido porque os clientes não fornecem ao tradutor informações suficientes à construção de um bom encargo. A autora orienta, então, que os tradutores sejam inquisitivos e que extraiam o máximo de informações de seus clientes a respeito do serviço encomendado. Na Figura 2, visualizamos como a autora entende o processo tradutório.

\footnotetext{
${ }^{8}$ Muitas da vezes iniciador e tradutor figuram como a mesma pessoa.
} 


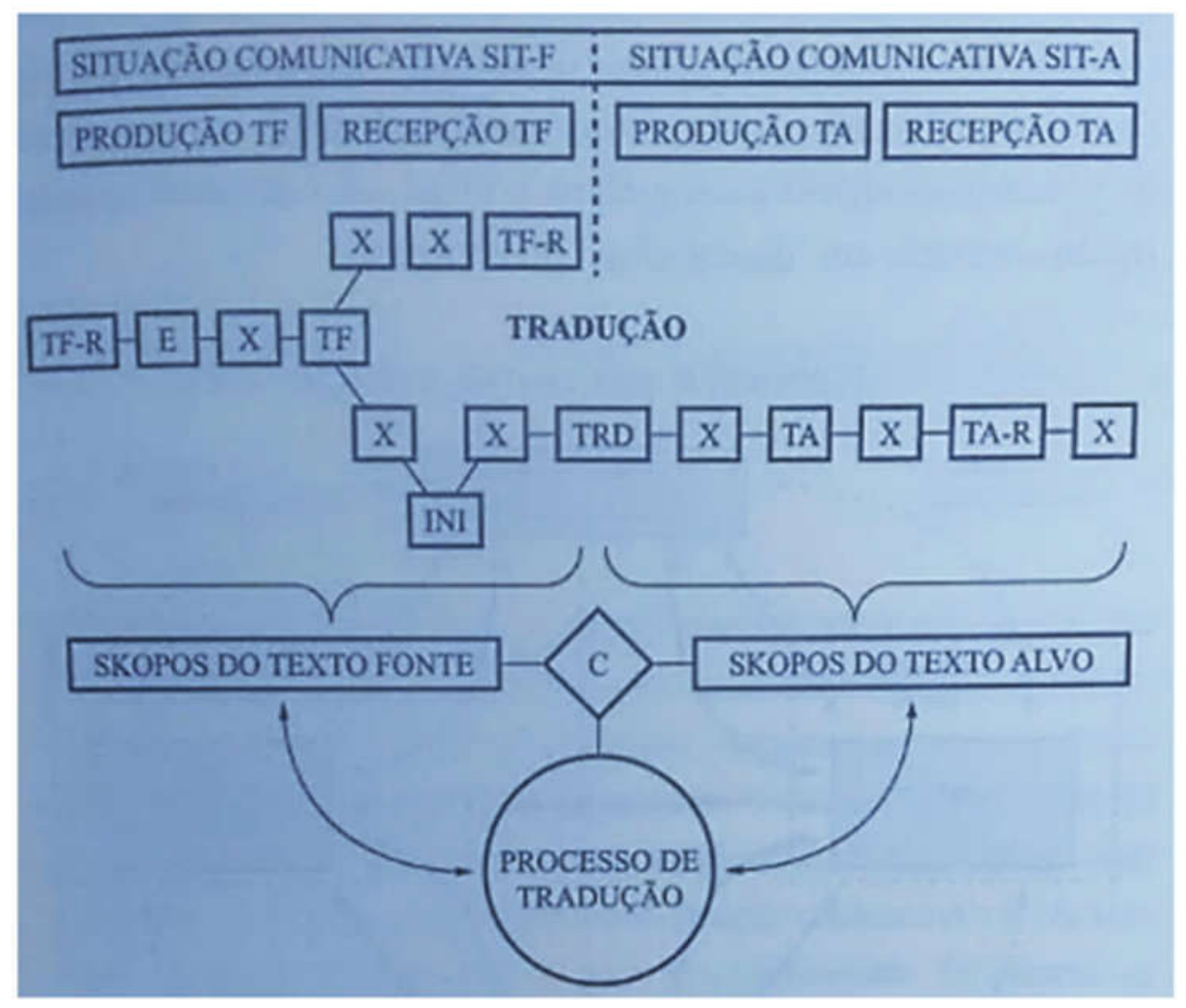

Figura 2: O processo de ação tradutória. Fonte: Nord (2016, p. 71)

Observa-se na Figura 2 que Nord segue uma cronologia do processo de produção textual envolvendo a tradução. Parte-se, pois, do autor e/ou do emissor para se chegar ao TF. Os elementos que permeiam o contexto ${ }^{9}$ de partida e de chegada ficam claros. O tradutor ocupa uma posição central por ser o mediador dessa comunicação intercultural, tomando parte no contexto de partida e de chegada. A autora põe o iniciador à parte, pois entende que esse é o local ao qual melhor se ajusta no processo tradutório. Ou seja, de posse do TF e pelo motivo X, o iniciador encomenda uma dada tradução. Note-se, também, que Nord usa a letra $\mathrm{X}$ em alguns espaços desse esquema por entender que os elementos previstos em sua teoria não são a totalidade do que está envolvido no processo tradutório, podendo outros elementos e variáveis aparecer durante esse processo.

$\mathrm{O} \mathrm{TF}$, na teoria nordiana (seguindo a teoria do escopo), é considerado uma "oferta de informação". Isso implica em um maior desprendimento do TF como o guia para se chegar a um TA. Se realmente entendermos o TF como uma oferta de informação, podemos produzir TT que atendam melhor às nossas necessidades. Contudo, é fundamental ponderarmos dois pontos. Primeiro, este conceito não nos permite dizer que $o$ significado do TF está sendo acessado pelo público-alvo. Guiado pelas instruções do encargo de tradução, o tradutor seleciona alguns itens da oferta de informação da LF (originalmente direcionados

\footnotetext{
${ }^{9}$ Consideramos "contexto", neste trabalho, na perspectiva bakhtiniana. Assim, o conceito de contexto que usamos leva em consideração as situações comunicativas mais imediatas como também as situações mais amplas ou sócio-históricas. (BAKHTIN, 2006, p. 112-130).
} 
ao público de partida), e os processa para produzir uma nova oferta de informação na LA, a partir da qual o público-alvo, em sua cultura, seleciona o que considera ser significativo em seu contexto. Nestes termos, o processo de tradução é irreversível $^{10}$ (NORD 2001, p. 32).

Esse desprendimento do TF, apesar de trazer mais possibilidades de traduções, também faz com que o TA se distancie da primeira oferta de informação. Por isso, nesse caso, é natural que se esperem no TT características tão particulares que estas não são percebidas ou nem mesmo estão no TF. É isso que Nord põe em debate quando fala em irreversibilidade. Observemos, porém, como segundo ponto, que o TA não é uma oferta de informação convencional, sua ligação ao TF deve ser patente, como vemos a seguir:

[...] uma vez que a tradução é uma oferta de informação que remete a uma oferta de informação prévia, é esperado que se estabeleça alguma relação com seu texto-fonte correspondente. Vermeer chama essa relação de "coerência intertextual" ou "fidelidade". Isto é postulado como um princípio ulterior, chamado de "regra da fidelidade" (REISS; VERMEER, 1984, p. 114).

Novamente, como no caso da regra do Escopo, o ponto importante é que haja coerência intertextual entre o texto-fonte e o texto-alvo, enquanto a forma que este assume depende tanto da interpretação do tradutor, em relação ao textofonte, como do Escopo da tradução. Um tipo possível de coerência intertextual poderia ser uma total e fiel imitação do texto-fonte ${ }^{11}$ (NORD, 2001, p. 32).

Vimos, logo acima, uma variação do que historicamente foi concebido como tradução. O diferencial da teoria funcionalista está no destaque dado a alguns fatores extratextuais de grande importância. Apesar de o tratamento dado ao TT ser previsto em muitas teorias (JAKOBSON, 2003; NIDA, 2004; BENJAMIN, 2010; ECO, 2011), o que não se percebe em sua maioria, no entanto, é uma discussão que ponha os fatores que estão em torno dele em relevo.

\footnotetext{
${ }^{10}$ This concept does not allow us to speak of the meaning of the source text being transferred to the target receivers. Guided by the translation brief, the translator selects certain items from the source-language offer of information (originally meant for sourceculture addressees) and processes them in order to form a new offer of information in the target language, from which the target-culture addressees can in turn select what they consider to be meaningful in their own situation. In these terms, the translation process is irreversible.

${ }^{11}$ [...] since a translation is an offer of information about a preceding offer of information, it is expected to bear some kind of relationship with the corresponding source text. Vermeer calls this relationship "intertextual coherence" or "fidelity". This is postulated as a further principle, referred to as the "fidelity rule" (Reiss and Vermeer 1984, p. 114). Again, as in the case of the Skopos rule, the important point is that intertextual coherence should exist between source and target text, while the form it takes depends both on the translator's interpretation of the source text and on the translation Skopos. One possible kind of intertextual coherence could be a maximally faithful imitation of the source text.
} 
Com frequência, os elementos destacados estão relacionados diretamente à constituição material do TF. Contudo, é preciso notar que mesmo entendendo-se um texto como uma oferta de informação, partindo-se de um escopo e de um encargo de tradução, não se pode produzir qualquer TT sem que antes se observe o princípio da lealdade.

Lealdade, diferente de fidelidade, toma, mais uma vez, um caráter prospectivo. A lealdade tradutória está exatamente na observação do respeito aos partícipes da ação comunicativa, a saber: o autor do TF, que não pode ter o seu texto manipulado de qualquer forma (respeito à produção intelectual); o iniciador (contratante do TT, cliente) que espera o respeito ao que foi acordado no encargo de tradução; o receptor (público de chegada) que tem expectativas em relação ao TT; e o próprio tradutor que deve ter princípios profissionais para não incorrer naquilo equacionado ao mercenarismo, isto é, produzir qualquer TT com base apenas em um escopo de tradução (NORD 2006a). Aqui, materialidade do texto não é desconsiderada, mas as pessoas envolvidas nessa ação, bem como o contexto comunicativo, ganham relevo ${ }^{12}$ (NORD, 2006a). Por ser uma teria abrangente, $\mathrm{o}$ funcionalismo tradutório aplica-se a diversas situações comunicativas. Vejamos, brevemente, a aplicabilidade desse quadro teórico a duas áreas bem distintas: o ensino de LE e a tradução literária.

\section{ALGUMAS APLICAÇÕES DO FUNCIONALISMO TRADUTÓRIO}

Trazemos à baila aplicações do Funcionalismo tradutório em uma sala de aula de LE, mostrando como seus pressupostos podem auxiliar professores e alunos, e também na Literatura, exemplificando com um romance italiano traduzido para o português brasileiro (PB).

\subsection{Tradução funcionalista em sala de aula de LE}

Os pressupostos da teoria funcional da tradução (como a noção de escopo e encargo) fornecem instrumentos para que, em sala de aula de LE, professores e alunos possam produzir TT com maior liberdade, rompendo a relação histórica de servilismo entre TF e TA. Essa ruptura pode ser produtiva ao aprendizado de LE, por exemplo, na tradução de idiomatismos. Ao acessar e analisar um idiomatismo

\footnotetext{
${ }^{12}$ De forma ilustrativa, Nord (2009, 210-211) supõe uma situação, em Jacarta, em que alguém que não domina a língua indonésia pede a uma amiga que solicite informações a um policial sobre determinado endereço. Esse policial, mesmo não sabendo onde fica o lugar, fornece uma descrição detalhada de como encontrar o tal endereço, porque em sua cultura eles evitam dizer que não sabem. A amiga em questão conhece tanto a língua como a cultura indonésia e traduz a explicação elaborada do policial como "ele não sabe onde fica".
} 
na LE, o aprendiz pode ter maior liberdade linguístico-cultural para produzir o seu TT, valorizando, assim, as suas próprias língua e cultura, produzindo textos em língua materna mais idiomáticos. Rompe-se, assim, a ideia de que a tradução deve ser biunívoca. É fundamental, nesse ponto, que os aprendizes entendam que a língua é apenas uma parte de uma cultura maior e que a produção de TF e TT é circunstanciada por contextos culturais e sócio-históricos mais amplos (2006b; NORD, 2012).

A abordagem funcionalista nos informa que em sala de aula de LE enunciados do tipo "leia e traduza" não são aceitáveis. É necessário, portanto, que o professor de LE, ao propor atividades de tradução, forneça ou negocie com os alunos encargos de tradução claros, definidos nessa teoria como "encargo didático de tradução" (NORD, 2009). Quando bem orientados sobre como, por que e para que traduzir, os aprendizes de LE podem produzir TT melhores e aprenderem mais durante o processo.

No que se refere às orientações de investigação dos elementos extratextuais e intratextuais do TF, esse quadro teórico pode ser bastante útil aos professores de LE, sobretudo na escolha dos TF que são usados em sala de aula. De posse desse instrumento de análise textual, esses profissionais têm a possibilidade de escrutinar os materiais que serão usados como textos de partida em suas aulas.

\subsection{Escolhas funcionais na tradução literária: o caso Andrea Camilleri}

Andrea Camilleri é um escritor, diretor e roteirista italiano, da Sicília, de 92 anos. Escreveu, até 2017, 106 livros, chegando a mais de 18 milhões de cópias, à tradução para 35 línguas e tendo mais de 40 filmes televisivos baseados em suas histórias, exibidos em todos os continentes.

O texto camilleriano apresenta a peculiaridade de ser um híbrido de língua italiana standard e dialeto siciliano (além de eventualmente outras línguas e dialetos), tanto nos diálogos, quanto na voz do narrador, com a função de trazer à tona representações culturais do locus dos envolvidos nas histórias.

Um exemplo é o último título do autor siciliano lançado no Brasil, o romance La rivoluzione della luna (2013), traduzido como A Revolução da lua (2015), por Joana Angélica D’Ávila Melo, publicado pelo Grupo Record.

O romance se passa na Sicília de 1677, quando a Espanha governava a ilha. Camilleri conta com criatividade o reinado de Dona Eleonora de Moura, sucessora do trono após a morte do seu marido, o vice-rei Don Angel de Guzman, combinando realidade e fantasia.

La rivoluzione della luna é escrito basicamente em italiano standard e dialeto siciliano, como podemos verificar no trecho (1), com negrito nosso para os termos em siciliano: 
La siduta del Sacro Regio Consiglio che il Viciré don Angel de Guzmán, marchisi di Castel de Roderigo, tiniva a Palazzo ogni matina di mircoldì alle deci spaccate, macari quel jorno, che era il tri di settembriro del milli e seicento e sittantasetti, accomenzò come a 'u solito, seguenno 'na procidura rigidamenti stabilita'. Camilleri (2013, p. 11)

Em seguida, apresentamos a tradução do excerto em (2):

A sessão do Sacro Régio Conselho que o Vice-Rei don Angel de Guzmán, marquês de Castel de Rodrigo, realizava no Palácio todas as manhãs de quarta-feira às dez em ponto, inclusive naquele dia, que era o 3 de setembro de 1677, começou como de hábito, seguindo um procedimento rigidamente estabelecido. Camilleri (2015, p. 11)

Verifica-se em (2) que a tradução opta por não considerar o híbrido linguístico, fazendo uso somente do $\mathrm{PB}$, exceto pelo título don, que se mantém em espanhol. Embora o texto camilleriano seja pleno de material linguísticocultural, através do uso do dialeto siciliano, essa característica não é transportada para o TT, não somente nesta obra, mas em todas as outras traduções das obras camillerianas para o $\mathrm{PB}$.

Porém, ainda no romance La rivoluzione della luna, há outra situação a ser explicitada: à fala da vice-rainha, que é espanhola, Camilleri confere um híbrido de italiano standard, siciliano e espanhol. Segue o excerto (3), com negrito nosso, para exemplificar:

"Yo soy Eleonora de Guzmán, marquesa de Castel de Rodrigo y domando la palabra." Camilleri (2013, p. 36)

$\mathrm{Na}$ tradução para o $\mathrm{PB}$ em (4), com negrito nosso, muitos trechos em espanhol são mantidos:

"Yo soy Eleonora de Guzmán, marquesa de Castel de Rodrigo, e peço la palabra." Camilleri (2015, p. 26)

A abordagem prospectiva da tradução com viés funcionalista valoriza o leitor e o contexto de chegada, produzindo um TT negociado no encargo de tradução, entre editora e tradutor, para alcançar um objetivo, um escopo. Em (2), não é possível que o TT, em PB, apresente dialeto siciliano, uma vez que seria ininteligível para o leitor brasileiro, pela diferença linguística. Diferentemente do que acontece em (4), em que há elementos em espanhol misturados ao PB, visto que o idioma castelhano não é uma grande barreira para o leitor brasileiro. 


\section{CONSIDERAÇÕES FINAIS}

O funcionalismo tradutório propõe um processo de rompimento dos paradigmas que punham o TA em posição servil em relação ao TF. Diferentemente das abordagens retrospectivas, que se baseiam essencialmente no texto de partida, a corrente funcional da Tradução considera em grande medida a situação de produção do $\mathrm{TT}$, bem como o contexto do texto de chegada. $\mathrm{O}$ processo de tradução deixa de ser algo essencialmente linguístico e passa a valorizar as questões culturais, sejam no TA como no TT, que fazem parte de sistemas culturais diferentes.

Desse modo, os partícipes da ação tradutória ganham tanta relevância quanto os elementos da arquitetura do $\mathrm{TF}$, atendendo diretamente ao encargo tradutório estabelecido. As aplicações desse quadro teórico são diversas. Aqui, optamos por tocar o ensino de LE e a tradução literária por serem as áreas de pesquisa dos autores deste trabalho.

\section{REFERÊNCIAS}

BAKHTIN, Mikhail. "A interação verbal". In: linguagem. São Paulo: Hucitec, 2006, p. 112-130. . Marxismo e filosofia da

BENJAMIN, Walter. "A Tarefa do Tradutor" (1923). Tradução Susana Kampff Lages. In: WERNER, H. (Org.). Clássicos da Teoria da Tradução. Volume 1, Alemão-Português. $2^{\circ}$ ed. Florianópolis: UFSC/Núcleo de Pesquisas em Literatura e Tradução, 2010, p. 202-230.

CAMILLERI, Andrea. La rivoluzione della luna. Palermo: Sellerio, 2013. - A revolução da lua. Tradução Joana Angélica D’Ávila Melo. Rio de Janeiro: Bertrand Brasil, 2015.

ECO, Umberto. Quase a mesma coisa. Rio de Janeiro: Best Bolso, 2011, p. 403.

JAKOBSON, Roman. Linguística e Comunicação. 19 ed. São Paulo: Cultrix, 2003, p. 63-72.

FAVERI, Cláudia Borges; TORRES, Marie-Hélène, Catherine (Org.). Clássicos da Teoria da Tradução. v. 2. Florianópolis: Núcleo de Tradução - Universidade Federal de Santa Catarina, 2004, p. 14-151.

FURLAN, Mauri (Org.). Clássicos da teoria da tradução. Florianópolis: Núcleo de Tradução da Universidade Federal de Santa Catarina, 2006, p. 52-129.

GUERINI, Andreia; ARRIGONI, Maria Teresa (Org.). Clássicos da teoria da tradução. Florianópolis: UFSC, 2005, p. 221. 
HEIDERMANN, Werner (Org.). Clássicos da Teoria da Tradução. 2. ed. Florianópolis: UFSC/Núcleo de Pesquisas em Literatura e Tradução, 2010, p. 344 .

LYONS, John. Linguagem e linguística - uma introdução. Tradução Marilda Winkler Averbug e Clarisse Sieckenius de Souza. Rio de Janeira: Editora Guanabara Koogan S.A, 1987, p. 299.

NIDA, Eugene. Principles of Correspondence. In: VENUTI, Lawrence (Ed.). The Translation Studies Reader. New York: Routledge: 2004, p. 126-140.

NORD, Christiane. Análise textual em tradução: bases teóricas, métodos e aplicação didática. Tradução e adaptação coordenadas por Meta Elisabeth Zipser. São Paulo: Rafael Copetti Editor, 2016.

. El funcionalismo en la enseñanza de traducción. Medellín: Mutatis Mutandis, 209, p. 209-243, 2009. Acesso em: 5 set. 2016. Disponível em: $<\underline{\text { https://dialnet.unirioja.es/servlet/articulo? codigo }=3089531}>$.

. Las funciones comunicativas en el proceso de traducción: un modelo cuatrifuncional. Caracas: Núcleo, 2010, p. 239-255. Disponível em: $<$ http://www.scielo.org.ve/pdf/nu/v22n27/art10.pdf $>$. Acesso em: 5 set. 2016.

Loyalty and Fidelity in Specialized Translation. Confluências - Revista de Tradução Científica e Técnica, [S.1.], n. 4, 2006a. p. 29-41. Acesso em: 5 set. 2016. Disponível em: <http://web.letras.up.pt/egalvao/TTCIP Nord loyatly and fidelity.pdf $>$.

. Quo vadis, functional translatology? Amsterdam: Target, 2012, p. 26-42.

- Text Analysis in Translation: theory, methodology, and didactic application of a model for translation-oriented text analysis. New York: Rodopi, 2005, p. 257.

- Translating as a Purposeful Activity: Functionalist Approaches Explained. Shanghai: Shanghai Foreign Language Education Press, 2001, p. 154.

- Translating for Communicative Purposes across Culture Boundaries. Journal of Translation Studies, [S.1.], 9 (1), 2006b. p. 43-60. Disponível em:

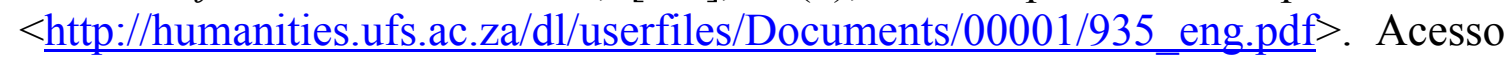
em: 5 set. 2016.

REISS, Katharina. Type, kind and individuality of text - Decision making in translation. Translated by Susan Kitron. In: VENUTI, Lawrence (Ed.). The Translation Studies Reader. New York: Routledge: 2004, p. 160-171.

SILVA, Kalina Vanderlei; SILVA, Maciel Henrique. Dicionário de conceitos históricos. São Paulo: Contexto, 2009. 
SNELL-HORNBY, Mary. The turns of Translation Studies. In: GAMBIER, Yves; DOORSLAER, Luc van (Ed.). Handbook of translation studies. v. 1. Amsterdam: John Benjamins, 2010, p. 366-370.

VENUTI, Lawrence (Ed.). Introduction. In: . The Translation Studies Reader. New York: Routledge, 2004, p. 1-18.

VERMEER, Hans-josef. Skopos and Commission in Translational Action. Translated by Andrew Chesterman. In: VENUTI, Lawrence (Ed.). The Translation Studies Reader. New York: Routledge: 2004, p. 221-232.

Rafael Ferreira da Silva Rafael.Ferreira@letras.ufc.br

Bill Bob Arinos Lima e Sousa Bill.Sousa@ifce.edu.br

Recebido em: 28/9/2017

Aceito em: 19/2/2018

Publicado em Abril de 2018 